\title{
Perceptions of international strategic moves: Saudi Arabia versus the United States
}

\author{
C.J. Robertson ${ }^{a}$ *, M.A. Yaghmour ${ }^{b}$ and E.H. Kawther ${ }^{c}$ \\ anternational Business and Strategy Group, D’Amore-McKim School of Business, \\ Northeastern University, 313 Hayden Hall, Boston, MA 02115 \\ ${ }^{b}$ Department of Business Administration, Faculty of Economics and Administration, King Abdulaziz University, Jeddah, Saudi Arabia \\ ${ }^{c}$ Faculty of Economics and Administration, King Abdulaziz University, Jeddah, Saudi Arabia \\ *To whom all correspondence should be addressed \\ c.robertson@neu.edu
}

\begin{abstract}
Competitive strategy is one of the most important activities that top management team members can undertake. In the global marketplace perceptions of strategic moves and plausible foreign markets to enter can vary based on cultural differences, economic conditions and past experiences. In this study we match the Miles and Snow strategic orientations with possible entry into different foreign markets. An in-depth survey of strategic orientation perceptions is developed and, based on a two-country research design, we obtain responses from 89 individuals from The United States and Saudi Arabia. A review of literature related to strategic orientation and cultural differences is performed and results suggest differences in perceptions of strategic preference and rating of promising foreign markets between the two national cohort groups. Three salient hypotheses are tested and supported related to topics such as where individuals prefer to invest, cultural distance and economic systems. Our differentiating contributions are (a) methodological, we use survey data rather than archival firm data as well as vignettes, and (b) theoretical, we assess managerial perceptions of foreign entry choice as opposed to firm level decisions. Managerial and future research implications are also discussed.
\end{abstract}

\section{Introduction}

Globalization and competition are phenomena that have merged to create an increasingly dynamic business landscape in which managers must continually assess their performance and competitive advantage relative to new and existing rival firms. Indeed, one major tool for sharpening one's ability to compete is understanding competitive strategy and diverse perceptions of strategic moves around the world. As more firms enter the global arena attaining a deeper comprehension of how managerial perceptions of strategic decisions from different cultures vary will become increasingly important (Chatterjee, Lubatkin, Schweiger \& Weber, 2006; Liang, Musteen \& Datta, 2012).

The purpose of this study is therefore to empirically examine perceptions of strategic orientation preferences when given choices of diverse foreign market opportunities. Our focus is specifically on the four key strategic orientations, Prospectors, Defenders, Analysers and Reactors, that were developed initially by Miles and Snow (1978) and have subsequently been utilized in a wide range of studies (i.e. Boyd \& Salamin, 2001; Rajagopalan, 1997). Although prior firm level studies of this topic have been conducted primarily in developed nations of Europe, North America and Asia (i.e. the United States, Spain, Japan) little evidence from emerging economies such as Saudi Arabia exists (Aragon-Sanchez \& Sanchez-Martin, 2005; Bird \& Beechler, 1995, Chan 2010; Hsu, Lien \& Chen, 2013). Moreover, this study builds upon a recent article published by Liang, Musteen and Datta (2009) in which the choice of foreign entry mode was examined in light of firm strategic orientations.

To contrast different managerial perceptions we have selected one economically powerful OECD (Organisation for Economic Co-Operation and Development) member, the United States, and one non-OECD member with a robust and growing economy, Saudi Arabia. Two way trade (exports plus imports) between the United States and Saudi Arabia has increased substantially in recent years with a total of $\$ 43$ billion in 2010 (www.ustr.gov). This represents the United States' 15th largest goods trading relationship (www.ustr.gov). Due to the increase of trade between United States and Saudi firms the current study should resonate with management scholars. Further, strategy has been primarily studied from a Western ideological perspective so obtaining and analysing information from Saudi Arabian managers will indeed make a contribution to the international strategy literature. Indeed, the interaction between developed and emerging market values as a result of different philosophical approaches to governance is inevitable to some extent.

Research related to international strategy has blossomed in the past two decades yet the emphasis on strategic thought and action in the Middle East has been largely overlooked (Sohail, 2012). The Middle East has made the news for a variety of reasons in the past decade and now appears to have global presence and as more emerging and transitional economies engage in trade with partners from developed nations bridging the gap in what is considered in the local context will rise in importance. As more firms formalize the role of strategic 
moves by rival firms from different nations of this region competitive analyses will be of keen interest to internal and external stakeholders (Kumar \& Rose, 2012).

The overarching aim and goal of this study is therefore to examine perceptions of international strategic moves in the United States and Saudi Arabia. Not only is the Saudi business environment of special interest to the United States but it is also a salient topic to researchers due to its unique economic model and current investment in economic diversification by encouraging growth in industries beyond oil and gas. Although the Saudi business environment is unique in the Middle East it also lacks some essential components such as professional analysis community and financial databases (Al-Razeen \& Karbhari, 2004; Robertson, Al-Alsheikh \& Al-Kahtani, 2012). Moreover, the cultural complexity in Saudi Arabia stands out when interfaced with Western nations such as the United States and this made Saudi Arabia an appealing country choice for this study.

From a theoretical perspective we ground our study in the two domains: first, we examine the strategic orientations developed by Miles and Snow (1978) and second, we assess cultural differences between Saudi Arabia and the United States (Liang et al., 2009). In the next section of this paper pertinent literature is reviewed and formal hypotheses are posited. Next, the methodology and results are discussed. The paper concludes with an assessment of managerial and future research implications.

\section{Literature review}

\section{Strategic orientations}

As firms expand geographically to different nations they must consider how effective their competitive strategy will be given diverse business environments and competitors with unique strategies. Miles and Snow (1978) developed four strategic orientations that can be adapted to different business environments and have been examined by numerous scholars (i.e. Aragon-Sanchez \& Sanchez-Martin, 2005; Bird \& Beechler, 1995, Kabanoff \& Brown, 2008. The first strategy is the Prospector. Firms that compete with this strategy focus primarily on innovation. These firms tend to focus externally and frequently adapt and adjust their product lines to fit different markets (Miles \& Snow, 1978; Liang et al., 2009). Prospectors are essentially pioneers that seek to expand rapidly and explore new opportunities. The second strategic type is the Defender. Firms that compete as Defenders focus simultaneously on efficiency and lowering costs (Liang et al., 2009). Defenders tend to be internally-oriented and are limited in their ability or desire to develop new products.

The third strategic type is classified as Analysers. Firms that compete with this strategy, which is essentially a hybrid approach, explore new opportunities and efficiency simultaneously (Miles \& Snow, 1978;) and this may be particularly salient in the context of small and medium sized enterprises (SMEs) (Raju, Lonial \& Crum, 2011). As Ghosh et al. (2001) suggest Prospector and Analyser strategic types tend to view regionalization quite sceptically with Analysers putting more emphasis on data collection and competitive analyses prior to making a market entry decision. Analysers tend to exploit current markets while exploring plausible opportunities that are on the horizon. The final strategic orientation is the Reactor. Reactors are firms that do not have a clear strategy and have core organizational problems (Liang et $a l ., 2009)$. These firms tend to fall behind rivals with respect to performance, innovation and efficiency.

Scholars have studied the Miles and Snow typology from different theoretical lenses, industries and in different national contexts (Chen, 2010; Liang et al., 2009). Moreover, researchers have linked the Miles and Snow strategies to investment patterns Hambrick (1983), risk orientations (James \& Hatten, 1995), knowledge creation (DiBenedetto \& Song, 2003) and other organizational phenomena such as strategy/structure alignment (Grøgaard, 2012). Documented differences related to managerial behaviour include: prospectors spend more on research and development and are more aggressive with marketing, defenders are more conservative with technology creation and reward long-term orientation (Hambrick, 1983; Rajagopalan, 1997). Based on the prior research mentioned above it appears plausible that managers from different institutional and cultural contexts, such as the United States and Saudi Arabia, are likely to possess different views related to risk aversion and investment preferences. Additionally, perceptions of the Miles and Snow strategies matched with different cultural and economic conditions may likely vary when given a choice of strategic orientation depending on the target expansion country.

\section{Contrasting Saudi Arabia and the United States}

Cultural distance refers to the gap between two or more cultures with respect to core values that exist in each society (Kogut \& Singh, 1988). For example, the cultural distance between the United States and Canada (with the exception of Quebec) would be low and the United States and Canada high (Hickson and Pugh, 1995). Due to the impact of religious traditions, historical patterns, economic and legal precedents the cultural distance between the United States and Saudi Arabia seems quite large. A deeper exploration of Saudi cultural influences should confirm this suspicion.

Islam's influence on Saudi Arabian culture has been very powerful. According to Hickson and Pugh (1995), there are four unique influences on Arab values: foreign rule, the Western quest for oil, Bedouin/tribal traditions, and Islam. The scope and magnitude of influence of each factor tends to vary from country to country and it is this variation that creates cultural, ethical and behavioural differences across the region. The variation in these factors also determines the extent to which each nation is more or less open to convergence, divergence, or crossvergence (Robertson, et al., 2012).

Researchers have also found that a national tendency toward a certain economic ideology can have an effect on how 
managers perceive issues such as ethical dilemmas, strategic moves and international expansion (Begley \& Tan, 2001; Ralston, Holt, Terpstra, \& Kai-Cheng, Y., 1997; Robertson \& Crittenden, 2003). Cultural traits and categories such as social status, proclivity for entrepreneurial behaviour and overarching work values have been found to vary between Anglo-Saxon/Western societies and Middle Eastern and Asian societies (Begley \& Tan, 2001; Robertson et al., 2012). Ralston et al. (1997) found that a matrix of cultural values (measured by individualism vs. collectivism) and economic ideology (capitalism vs. communism) yields four institutional categories with differences among the four groups. Indeed, the two nations of interest in the current study tends to lean in different directions, with the United States more individualist/capitalist and Saudi Arabia more collectivist/mixed (capitalist, communist).

Turning to strategy perceptions, local partnership is required from any foreign investor interested in entering the Saudi market. The Saudi partner must have majority ownership and the requirement of any expatriate worker entering the country must have a local sponsor (Robertson, et al., 2012). Saudis tend to adhere to a strict Islamic code of conduct and any strategic moves that could potentially violate the code will likely be averted (Malek, Vacani, Rasquinha, \& Davey, 1993). Further, the religious and ethnic homogeneity of Saudi Arabia has made it a much easier task, politically and socially, for the Saudi government to reinforce a strict Islamic code of conduct among its people than in the relatively more diverse nations such as Egypt and Kuwait.

It is plausible that value variation between the United States and Saudi Arabia stems from the Islamic beliefs and the extent to which each nation upholds Muslim beliefs in their respective legal, political and business environments (Ali, 1990). Saudi Arabia is arguably the most fundamental and devoted Muslim state. Being the birthplace of Islam and the location of the two holy shrines, Mecca and Medina, for approximately one quarter of the world population, the Saudis have assumed the religious leadership position for Muslims around the globe. With such politically as well as socially sensitive role, the Saudis have maintained rigid controls on the social and moral code of conduct of their people through the strictest adherence to the holy Qur'an which plays a major role in every facet of Saudi life (Hickson \& Pugh, 1995).

Other researchers have concluded that Saudi Arabians and citizens of the United States differ along a number of cultural dimensions including individualism (United States is higher), economic ideology, corporate governance, ethical orientations, human resource management practices and citizenship (see Ali, 1990; Mellahi, 2007; Ralston et al., 1997; Robertson et al., 2002; 2012). Based on the above analysis we have developed the following Hypotheses for testing:

\begin{abstract}
Hypothesis 1. When faced with different strategic orientation investment options Saudi Arabian managers will place more emphasis than managers from the United States on the economic system than the culture of the target foreign market.
\end{abstract}

Hypothesis 2. Decisions to invest in firms that pursue certain strategic orientations (defender, prospector, reactor, analyser) will be positively related to overall perceptions of that given strategy regardless of cultural distance.

Hypothesis 3. United States and Saudi Arabian managers will differ in their perceptions of strategic investment decisions that contain cultural distance.

\section{Methodology}

\section{Survey Instrument Development}

Data were collected in Saudi Arabia and the United States using a survey instrument that was created and pre-tested in the summer of 2012. The survey construction was based on the development of scenarios that reflect the Miles and Snow strategies and place respondents in a situation where they assess the matching of each strategy with different home and host countries for foreign investment. Pretesting occurred with graduate students from the United States as well as and Professors from both Saudi Arabia and the United States. Due to local context, the English version of the survey was translated to Arabic by a bilingual Saudi national and adapted as necessary without losing the scope or spirit of the constructs. Respondents were informed that their participation was voluntary and that their responses were completely anonymous (Alreck \& Settle, 1995).

The survey consisted of three sections. In the first section respondents were asked to rate, on a 7 point Likert scale, six different countries along two dimensions: capitalism versus socialism, and individualism versus collectivism. The included countries were the following: United Kingdom, Japan, Russia, China, Saudi Arabia, the United States and Peru. The second section was designed to measure perceptions of the four Miles and Snow strategies when faced with expansion into the United Kingdom, Japan, Russia and China. Respondents received short vignettes (see Appendix 1 for samples) describing firms with strategies similar to Prospectors, Analysers, Defenders and Reactors. Each respondent was then asked to rate the potential for success of a Defender expanding from their home country to the United Kingdom, Japan, Russia and China. A follow up question related to rating whether or not respondents would invest in the depicted firm was asked next. This process of questioning was repeated until each respondent evaluated all four strategic orientations for the four highlighted nations. The third section of the survey contained questions about the demographic profile of each participant in the study. Our questions included the following: education, managerial level, religion, gender, marital status, age, firm type, 
industry, firm size and whether or not the respondent's firm had international operations.

\section{Analytical procedures and results}

The final number of usable surveys yielded a total sample size of 89 professionals ( $n=46$ for Saudi Arabia and 43 for the United States). In Table 1 a list of demographic variables and percentages for each group is presented. The 89 respondents represented a cross-section of Saudi and United States citizens. Data were collected through evening graduate and certificate programs in each country and every attempt was made to secure comparable samples from each national cohort. The average age of the Saudi group was 29.7 years compared to 25.9 for the group from the United States. With respect to education both groups contained a vast majority with either a Bachelor's or Master's degree (Saudi 86.9\% and United States 97.6\%). In Saudi Arabia $69.8 \%$ of the respondents indicating that they were in junior, mid or executive level positions compared to $76.9 \%$ for the United States sample. $47.8 \%$ of the Saudis worked for large firms, of over 500 employees, compared to $55.8 \%$ for the United States sample. The Saudi group of respondents was more male than the United States cohort with only $4.7 \%$ female in the Saudi group compared to $48.8 \%$ female for the United States.

Table 1: Demographic profile of respondents

\begin{tabular}{l|c|c}
\hline Variable & Saudi Arabia & U.S.A. \\
\hline Age & 29.7 years & 25.9 years \\
\hline Education & & \\
\hline High school & $2.2 \%$ & $0.0 \%$ \\
\hline B.S./B.A. & $23.9 \%$ & $48.8 \%$ \\
\hline Master's & $63.0 \%$ & $48.8 \%$ \\
\hline Doctorate & $12.2 \%$ & $0.0 \%$ \\
\hline Other & $8.7 \%$ & $2.4 \%$ \\
\hline Mgt Level & & $7.7 \%$ \\
\hline Executive & $11.6 \%$ & $25.6 \%$ \\
\hline Middle mgt & $44.2 \%$ & $43.6 \%$ \\
\hline Junior mgt & $14.0 \%$ & $23.1 \%$ \\
\hline Staff & $23.3 \%$ & $0.0 \%$ \\
\hline Other & $18.6 \%$ & \\
\hline Gender & & $51.2 \%$ \\
\hline Male & $95.3 \%$ & $48.8 \%$ \\
\hline Female & $4.7 \%$ & \\
\hline Firm Size & & $32.5 \%$ \\
\hline 50 or fewer & $28.3 \%$ & $2.3 \%$ \\
\hline 51 to 100 & $13 \%$ & $9.3 \%$ \\
\hline $101-500$ & $10.9 \%$ & $7.0 \%$ \\
\hline $501-1000$ & $8.7 \%$ & \\
\hline 1000 or more & $39.1 \%$ & \\
\hline Sample Size $(\boldsymbol{n})$ & & \\
\hline & & \\
\hline
\end{tabular}

Dependent and independent variables. The dependent variable was constructed based on the theoretical directionality of our hypotheses. First, we developed a two item measure of the strategic types Defender, Prospector and Analyser (we dropped Reactor from our analyses due to arguments that the Reactor isn't really a viable strategy). For example, one item read as follows, "White Company avoids change when possible and competes based on operational efficiency. If White Company decides to move from the United States to the United Kingdom how would you rate the potential success of this move?" The second dependent variable queried the respondents about whether or not they would invest in firm in the highlighted scenario. This process of questioning was repeated with a total of 48 questions related to different strategies and different countries. The Independent, predictor, variable were constructed by soliciting perceptions, along a 7-point Likert scale, on capitalism-socialism and individualism-collectivism for the following countries: United Kingdom, Japan, Russia, China, Saudi Arabia, United States and Peru.

To test Hypotheses 1 and 2 we performed regression analysis. The results from two-stage hierarchical regression analysis are presented in Table 2. A two-stage regression model was run six times ( 3 strategies $x$ two countries) and three models were significant at the $\mathrm{p}<.05$ level. The first two columns of results in Table 2 reveal the empirical analysis performed utilizing Defender as the dependent variable. The significant finding that United Kingdom economy, China economy, and Saudi Arabia economy $(p<.05$ ) were related to Saudi Defender strategy and only Saudi culture $(\mathrm{p}<.05)$ was linked to the United States. Defender lends support to Hypothesis 1 (When faced with different strategic orientation investment options Saudi Arabian managers will place more emphasis on the economic system than the culture of the target foreign market). This pattern carries out across the six regression equations with three Saudi economic variables and four United States cultural variables serving as significant predictors. 
Table 2: Regression results: Dependent variables: Strategic orientations

\begin{tabular}{|c|c|c|c|c|c|c|}
\hline & Defender & Defender & Prospector & Prospector & Analyser & Analyser \\
\hline & Saudi Arabia & U.S.A. & Saudi Arabia & U.S.A. & Saudi Arabia & U.S.A. \\
\hline \multicolumn{7}{|l|}{ Control Variables } \\
\hline Education & -.22 & -.11 & .16 & .20 & .29 & $.58 *$ \\
\hline Mgt Level & .01 & -.11 & $.46^{*}$ & .21 & .18 & .08 \\
\hline Gender & -.51 & .52 & -.61 & .25 & $-.13^{*}$ & .06 \\
\hline Age & .01 & .01 & .02 & -.03 & -.01 & -.05 \\
\hline Firm Size & -.06 & .05 & .09 & -.03 & -.01 & .08 \\
\hline \multicolumn{7}{|c|}{ Predictor Variables } \\
\hline UK economy & $.31 *$ & -.10 & .08 & -.02 & .26 & -.01 \\
\hline Japan economy & .03 & .05 & -.03 & .19 & -.11 & .09 \\
\hline Russia economy & -.14 & -.10 & .07 & .05 & .07 & $.29 *$ \\
\hline China economy & $.22 *$ & .04 & .15 & .07 & .18 & -.12 \\
\hline KSA economy & $-.30 *$ & .05 & .02 & .05 & .06 & -.09 \\
\hline USA economy & -.11 & -.08 & .24 & .09 & -.15 & -.06 \\
\hline Peru economy & .03 & .16 & -.19 & -.01 & -.09 & -.21 \\
\hline UK culture & .11 & -.02 & -.08 & -.12 & -.16 & $-.30 *$ \\
\hline Japan culture & .05 & .01 & -.08 & .03 & .10 & .03 \\
\hline Russia culture & -.12 & -.06 & -.06 & $-.22 *$ & -.05 & $-.26^{*}$ \\
\hline China culture & .13 & .03 & -.08 & .17 & -.11 & .07 \\
\hline KSA culture & .11 & $-.23 *$ & -.15 & -.09 & -.02 & -.02 \\
\hline USA culture & -.01 & .26 & .02 & .10 & .11 & .23 \\
\hline Peru culture & -.09 & -.08 & -.11 & -.08 & -.06 & -.10 \\
\hline Model $\mathrm{R}^{2}$ & .62 & .45 & .45 & .54 & .35 & .66 \\
\hline $\mathrm{F}$ & $2.01 *$ & .80 & $.99 *$ & 1.16 & .66 & $1.97 *$ \\
\hline
\end{tabular}

Third models are reported, data entered in three stages

Table 3: Regression results: Dependent variables: Strategic orientations

\begin{tabular}{|c|c|c|c|c|}
\hline & Defender & Prospector & Reactor & Analyser \\
\hline \multicolumn{5}{|c|}{ Control Variables } \\
\hline Education & -.01 & -.07 & .07 & .02 \\
\hline Mgt Level & .07 & .05 & -.04 & -.03 \\
\hline Gender & -.07 & -.01 & .02 & -.07 \\
\hline Age & .02 & -.02 & -.09 & -.09 \\
\hline Firm Size & -.03 & .07 & .03 & -.06 \\
\hline \multicolumn{5}{|c|}{ Predictor Variables } \\
\hline UK invest & $.30 * *$ & $.29 * *$ & $.42 * * *$ & $.23 * *$ \\
\hline Japan invest & .08 & $.36^{* * *}$ & $.21 *$ & $.37 * * *$ \\
\hline Russia Invest & $.18^{*}$ & $.20 *$ & $.22 * *$ & $.39 * * *$ \\
\hline China invest & $.29^{* *}$ & $.29^{* *}$ & $.32 * * *$ & $.23 * * *$ \\
\hline Model R ${ }^{2}$ & .35 & .58 & .84 & .72 \\
\hline $\mathrm{F}$ & $4.26^{* * *}$ & $13.21 * * *$ & $47.99 * * *$ & $20.39 * * *$ \\
\hline
\end{tabular}

Third models are reported, data entered in three stages

$* \mathrm{p}<.05 ; * * \mathrm{p}<.01 ; * * * \mathrm{p}<.001$ 
Table 4. T-Test group statistics (country 1 Saudi Arabia; Country 2 United States)

\begin{tabular}{|c|c|c|c|c|c|}
\hline & Country & $\mathbf{N}$ & Mean & Std. Deviation & $\mathbf{F}$ \\
\hline \multirow[t]{2}{*}{ UKeconomy } & 1.00 & 46 & 1.9783 & 1.74470 & .02 \\
\hline & 2.00 & 43 & 2.8372 & 1.61732 & \\
\hline \multirow[t]{2}{*}{ JAPeconomy } & 1.00 & 46 & 2.6304 & 2.06945 & $5.95 *$ \\
\hline & 2.00 & 43 & 2.7442 & 1.49751 & \\
\hline \multirow[t]{2}{*}{ RUSeconomy } & 1.00 & 46 & 5.4130 & 2.21687 & $3.05^{*}$ \\
\hline & 2.00 & 43 & 4.7442 & 1.69162 & \\
\hline \multirow[t]{2}{*}{ CHIeconomy } & 1.00 & 46 & 5.6304 & 1.79330 & 1.08 \\
\hline & 2.00 & 43 & 5.0000 & 1.87718 & \\
\hline \multirow[t]{2}{*}{ SAeconomy } & 1.00 & 46 & 3.1087 & 1.81632 & .44 \\
\hline & 2.00 & 43 & 4.1395 & 1.85910 & \\
\hline \multirow[t]{2}{*}{ USAeconomy } & 1.00 & 46 & 1.8478 & 1.73804 & .04 \\
\hline & 2.00 & 43 & 2.2791 & 1.68078 & \\
\hline \multirow[t]{2}{*}{ Perueconomy } & 1.00 & 46 & 3.7391 & 2.27484 & $18.70 * * *$ \\
\hline & 2.00 & 43 & 3.9767 & 1.29997 & \\
\hline \multirow{2}{*}{ UKculture } & 1.00 & 46 & 3.2609 & 2.14409 & $12.18^{* *}$ \\
\hline & 2.00 & 43 & 2.3953 & 1.39965 & \\
\hline \multirow[t]{2}{*}{ JApculture } & 1.00 & 46 & 4.6957 & 2.51104 & $5.94 *$ \\
\hline & 2.00 & 43 & 4.8372 & 1.90151 & \\
\hline \multirow[t]{2}{*}{ RUSculture } & 1.00 & 46 & 2.9565 & 2.07586 & $3.16^{*}$ \\
\hline & 2.00 & 43 & 4.6512 & 1.61664 & \\
\hline \multirow[t]{2}{*}{ CHIculture } & 1.00 & 46 & 4.2391 & 2.22296 & $23.05 * * *$ \\
\hline & 2.00 & 43 & 5.5581 & 1.25930 & \\
\hline \multirow[t]{2}{*}{ SAculture } & 1.00 & 46 & 3.4565 & 1.92881 & .01 \\
\hline & 2.00 & 43 & 4.3953 & 1.87895 & \\
\hline \multirow[t]{2}{*}{ USAculture } & 1.00 & 46 & 3.5652 & 2.26718 & $31.89 * * *$ \\
\hline & 2.00 & 43 & 1.7674 & 1.13047 & \\
\hline \multirow[t]{2}{*}{ Peruculture } & 1.00 & 46 & 2.8696 & 1.88100 & $6.56^{*}$ \\
\hline & 2.00 & 43 & 4.1628 & 1.25224 & \\
\hline \multirow[t]{2}{*}{ UKinvest } & 1.00 & 45 & 3.6000 & 1.82657 & $7.95 * *$ \\
\hline & 2.00 & 43 & 3.9535 & 1.30846 & \\
\hline \multirow[t]{2}{*}{ JAPinvest } & 1.00 & 45 & 3.5556 & 2.08409 & $7.75 * *$ \\
\hline & 2.00 & 43 & 3.6279 & 1.46423 & \\
\hline \multirow[t]{2}{*}{ RUSinvest } & 1.00 & 45 & 2.6000 & 1.54331 & .41 \\
\hline & 2.00 & 43 & 2.3953 & 1.39965 & \\
\hline \multirow[t]{2}{*}{ CHIinvest } & 1.00 & 45 & 3.9111 & 1.78150 & 1.04 \\
\hline & 2.00 & 43 & 4.0698 & 1.54912 & \\
\hline \multirow[t]{2}{*}{ UKPinvest } & 1.00 & 45 & 4.4000 & 1.40454 & 2.36 \\
\hline & 2.00 & 43 & 4.8140 & 1.11816 & \\
\hline \multirow[t]{2}{*}{ JAppinvest } & 1.00 & 45 & 4.4667 & 1.86596 & $5.44 *$ \\
\hline & 2.00 & 43 & 4.0233 & 1.43905 & \\
\hline RUSpinvest & 1.00 & 45 & 3.4667 & 1.61808 & 1.11 \\
\hline & 2.00 & 43 & 2.4651 & 1.31564 & \\
\hline Chipinvest & 1.00 & 45 & 4.0667 & 1.86353 & $4.58^{*}$ \\
\hline & 2.00 & 43 & 3.9070 & 1.37692 & \\
\hline UKainvest & 1.00 & 45 & 4.7778 & 1.74368 & $5.58^{*}$ \\
\hline & 2.00 & 43 & 5.0930 & 1.17136 & \\
\hline JAPainvest & 1.00 & 45 & 4.6889 & 1.54952 & .11 \\
\hline & 2.00 & 43 & 4.6279 & 1.36318 & \\
\hline RUSainvest & 1.00 & 45 & 3.5333 & 1.60397 & .22 \\
\hline & 2.00 & 43 & 3.1163 & 1.48339 & \\
\hline CHIainvest & 1.00 & 45 & 4.3778 & 1.59956 & .66 \\
\hline & 2.00 & 43 & 4.0000 & 1.49603 & \\
\hline
\end{tabular}

In Hypothesis 2 we proposed that decisions to invest in firms that pursue certain strategic orientations will be positively related to overall perceptions of that given strategy regardless of cultural distance. Table 3 reveals the results from regression analyses in which all four strategic orientations were set as dependent variables for the full sample (both countries). All four models were significant at the $p<.001$ level and 15 of the
16 'would you invest' variables were significant. The two strongest models were the Reactor (R-square of .84) and Analyser (R square of .72). Thus Hypothesis 2 is supported.

In Hypothesis 3 we posited that managers from Saudi Arabia and the United States will differ in their beliefs about investing in different nations. In Table 4 our results from Independent 
Samples t-tests reveal that managers from the United States have a significantly higher mean scores than the Saudi Arabian managers on eight variables while the Saudi Arabians scored higher on five variables. Based on our results, Hypothesis 3 is also supported.

\section{Discussion}

As more firms attempt to understand strategic moves in the global economy attaining an understanding of preferred strategies and nations of rivals will add value to opportunity assessments. Yet the extent to which incorporating local perceptions of strategy, economic system and cultural issues into a viable strategic framework can be extraordinarily country specific and many local institutions may choose to embrace deeply seeded and highly revered traditions. In Saudi Arabia an attempt to balance free market capitalism with the protection of highly valued cultural and religious traditions has led to a unique business environment (Robertson et al., 2012). The Saudi Arabian government has traditionally steered clear of micro-managing private sector activity yet with the Saudi Stock Market governmental authorities concluded that developing a reasonable governance structure would generate a healthier investment climate (Mellahi, 2007).

Managers working for Multinational Enterprises may indeed find our initial results interesting for a variety of reasons. First, very little information is available about how managers from non-OECD nations perceive strategic orientations such as Prospectors, Analysers and Defenders, especially in Saudi Arabia. Second, any firm that intends to engage in business in the Middle East may find it prudent to consider altering strategic moves and policies based on the local traditions, best practices and perceptions of external governance techniques (such as those set forth by the OECD). And third, firms may elect to seek adapt strategies to the competitive moves of rivals, which are based in part on rival evaluations and perceptions of what constitutes a strong competitive strategy. On a global scale the pattern of strategic moves and convergence versus divergence of values has significant implications for Multinational firms that view the world as one market.

Our support of all three hypotheses sets the stage for future research endeavours. In Hypothesis 1 we found that when faced with different strategic orientation investment options Saudi Arabian managers tend to place more emphasis on the economic system than the culture of the target foreign market. In Hypothesis 2 we concluded that decisions to invest in firms that pursue certain strategic orientations are positively related to overall perceptions of given strategies regardless of cultural distance. In our testing of Hypothesis 3 we revealed that respondents from the United States and Saudi Arabia differed across a number of perceptions when assessing the scenarios. For example, the group from the United States had a significantly higher perception of the Japanese economy and culture while the Saudi Arabian group rated the Chinese economy and U.K. culture higher.
A number of managerial implications exist based on the findings of this study. First, top management must understand that the institutional of each nation can be extremely fragile and can change rapidly. Indeed, this ebb and flow can affect perceptions of investment opportunities over time. There is no doubt that Saudi Arabia and American managers have many differences, yet they also embrace a number of similar values as well such as the desire to maximize shareholder's wealth and protect the investments of their firms at home and abroad. Nonetheless, obtaining an understanding of how managers from different nations perceive the efficacy of the Miles and Snow typology in unique market entry scenarios can add to our knowledge of perceptions of country brands and cultural misconceptions.

Any study that includes data collection in emerging economies can have some limitations. One limitation is that we have asked mid-level managers to assess strategic decisions that generally are made at the executive level of an organization. Despite this drawback, we do believe that the cultural perceptions of strategic opportunities shed light on an interesting phenomenon. Obtaining a sample with an even distribution of men and women in Saudi Arabia is a challenge due to a much higher percentage of the working population stemming from the male group due to religious and cultural reasons. Despite our samples being are slightly uneven with respect to certain demographic variables, such as age and gender, we do believe that our research questions have been more than adequately addressed and cultural differences have been captured in our analyses. Response bias is often a problem with survey administration and we hope that by using the same protocol in each nation we have been able to control this issue. Future researchers may elect to refine or expand the foundation established in this study by examining the link between Davenport's (2000) principles and other ethical phenomena.

The modern multinational organization has given more power to its professional managers away from its owners. To overcome this conflict of interest, companies use a set of rules and procedures known as corporate governance. A salient area for future research is to assess the impact that local citizenship related legislation has had on various performance measures ranging from market capitalization to annual financial performance to perceptual measures such as firm reputation. Moreover, as firms establish relationships with partners from culturally-diverse nations (via joint ventures, acquisitions, etc.) there is no doubt that some dialog surrounding ethics, standards and community interaction occurs. This would also be an interesting area for future researchers to examine. In sum, we believe that the results of this study have added breadth and depth to the body of knowledge related to cross-cultural ethics in general, and the multinational applicability of codes of ethics in particular. Further, this study has identified a number of salient future research endeavours for ethics scholars. Future researchers should examine perceptions of codes of ethics in Europe as well as other Asian and Latin American nations. A more in depth analysis of the drivers of attitudes about codes of ethics may also prove to be a 
rewarding avenue for research. Finally, external factors that play a causal role in the formation of attitudes about ethics codes, such as specific legal requirements and industry standards, could also be examined in the future.

\section{References}

Ali, A. 1990. 'Management theory in a transitional society: The Arab's experience', International Studies of Management and Organization, 20(3):7-35.

Al-Razzen, A., \& Karbhari, Y. 2004, 'Interaction between compulsory and voluntary disclosure in Saudi Arabia corporate annual reports', Managerial Auditing Journal, 19:351-360.

Alreck, P, \& Settle, R. 1995. The survey research handbook (2nd Edition), Homewood, IL: Irwin.

Aragon-Sanchez, A. \& Sanchez-Marin, G. 2005, 'Strategic orientation, management characteristics, and performance: A study of Spanish SMEs', Journal of Small Business Management, 43(3):287-308.

Begley, T.M., \& Tan, W.L. 2001. 'The socio-cultural environment for entrepreneurship: A comparison between East Asian and Anglo-Saxon countries', Journal of international business studies, 537-553.

Bird, A., \& Beechler, S. 1995. 'Links between business strategy and human resource management strategy in U.S.-based Japanese subsidiaries: An empirical investigation', Journal of International Business Studies, 26(1):23-46.

Boyd, B. \& Salamin, A. 2001, 'Strategic reward systems: A contingency model of pay system design', Strategic Management Journal, 22(8):777-792.

Chan, R.Y. 2010. 'Corporate environmentalism pursuit by foreign firms competing in China', Journal of World Business, 45(1):8092.

Chatterjee, S., Lubatkin, M.H., Schweiger, D.M., \& Weber, Y. 2006, 'Cultural differences and shareholder value in related mergers: Linking equity and human capital', Strategic Management Journal, 13(5):319-334.

Di Benetto, C, \& Song, X. 2003, 'The relationship between strategic type and firm capabilities in Chinese firms', International Marketing Review, 20(5):514-533.

Ghosh, B.C., Liang, T.W., Meng, T.T., \& Chan, B. 2001. 'The key success factors, distinctive capabilities, and strategic thrusts of top SMEs in Singapore', Journal of Business Research, 51(3):209-221.

Grøgaard, B. 2012. 'Alignment of strategy and structure in international firms: An empirical examination', International Business Review, 21(3):397-407.

Hambrick, D. 1983. 'On the staying power of defenders, analysers and reactors', Academy of Management Executive, 17(4):115-118.

Hickson, D., \& Pugh, D. 1995. Management Worldwide, Penguin Books: London.

Hsu, C.W., Lien, Y.C., \& Chen, H. 2013. 'International ambidexterity and firm performance in small emerging economies', Journal of World Business, 48(1):58-67.
James, W.L. \& Hatten, K. 1995. 'Further evidence on the validity of the self-typing paragraph approach: Miles and snow strategic', Strategic Management Journal, 16(2):161-168.

Kabanoff, B., \& Brown, S. 2007. 'Knowledge structures of prospectors, analysers, and defenders: Content, structure, stability, and performance', Strategic Management Journal, 29(2):149-171.

Kogut, B. \& Singh, H. 1988. 'The effect of national culture on the choice of entry mode', Journal of International Business Studies, 19(3):411-432.

Kumar, N. \& Rose, R. 2012. 'The impact of knowledge sharing and Islamic work ethic on innovation capability', Cross Cultural Management: An International Journal, 19(2):142 - 165.

Liang, X., Musteen, M, \& Datta, D. 2009. 'Strategic orientation and the choice of foreign market entry mode: An empirical examination', Management International Review, 49:269-290.

Malek, M., Vacani, P., Rasquinha, J., \& Davey, P. 1993. Managerial Issues in the Reformed NHS, West Sussex, England: Wiley.

Mellahi, K. 2007, 'The effect of regulations on HRM: Private sector firms in Saudi Arabia', International Journal of Human Resource Management, 18(1):85-99.

Miles, R., \& Snow, C. 1978. Organizational strategy, structure and process, New York: McGraw-Hill.

Rajagopalan, N. 1997. 'Strategic orientations, incentive plan adoption, and firm performance: Evidence from electric utility firms', Strategic Management Journal, 18(10):761-785.

Raju, P.S., Lonial, S.C., \& Crum, M.D. 2011. 'Market orientation in the context of SMEs: A conceptual framework', Journal of Business Research, 64(12):1320-1326.

Ralston, D.A., Holt, D.H., Terpstra, R.H., \& Kai-Cheng, Y. 1997. 'The impact of national culture and economic ideology on managerial work values: A study of the United States, Russia, Japan, and China', Journal of International Business Studies, 177207.

Robertson, C.J., \& Crittenden, W.F. 2003. 'Mapping moral philosophies: Strategic implications for multinational firms', Strategic Management Journal, 24(4):385-392.

Robertson, C., Al-Alsheikh, S. \& Al-Kahtani, A. 2012. 'An analysis of perceptions of western corporate governance principles in Saudi Arabia', International Journal of Public Administration, 35(6):402-409.

Robertson, C., Al-Khatib, J. \& Al-Habib, M. 2002. 'The relationship between Arab values and work beliefs: An exploratory examination', Thunderbird International Business Review, 44(5):583-601.

Sohail, S. 2012. 'Outsourcing the information technology function: Perspectives from employers', South African Journal of Business Management, 43(2):51-59. 


\section{Appendix 1: Strategic orientation vignettes}

Defender scenario. White Company avoids change when possible and competes based on operational efficiency. If White Company decides to move from the Saudi Arabia to the United Kingdom how would you rate the potential success of this move?

Prospector scenario. Green Company competes primarily on innovation and has a broad and changing product line. If Green Company decides to move from the Saudi Arabia to the United Kingdom how would you rate the potential success of this move?

Analyser scenario. Blue Company has more of a balanced strategy and competes by both exploring innovation and seeking operational efficiency in existing business units. If Blue Company decides to move from the Saudi Arabia to the United Kingdom how would you rate the potential success of this move?

Reactor scenario. Red Company lacks a clear and consistent strategy and has made inconsistent entrepreneurial choices. If Red Company decides to move from the Saudi Arabia to the United Kingdom how would you rate the potential success of this move? 